\title{
REGULATION OF THE DYNAMIC LIVE LOAD FAC- TOR FOR CALCULATION OF BRIDGE STRUCTURES ON HIGH-SPEED RAILWAY MAINLINES
}

\author{
Leonid K. DYACHENKO ${ }^{1, *}$, Andrey V. BENIN ${ }^{1}$ \\ ${ }^{1}$ Emperor Alexander I St. Petersburg State Transport University, 9 Moskovsky pr., St. Petersburg, \\ Russia, 190031 \\ corresponding author: leonid_dyachenko@mail.ru
}

\section{Abstract}

When the high-speed railway traffic is being organized, it becomes necessary to elaborate bridge design standards for high-speed railways (HSR). Methodology of studying the issues of HSR bridge design is based on the comprehensive analysis of domestic research as well as international experience in design, construction and operation of high-speed railways. Serious requirements are imposed on the HSR artificial structures, which raise a number of scientific tasks associated mainly with the issues of the dynamic interaction of the rolling stock and the bridge elements. To ensure safety of traffic and reliability of bridges during the whole period of operation one needs to resolve the dynamic problems of various types of high-speed trains moving along the structures. The article analyses dependences of the magnitude of inertial response on the external stress parameters and proposes a simplified method of determination of the dynamic live load factor caused by the passage of high-speed trains. The usefulness of the given research arises from the reduction of complexity of the complicated dynamic calculations needed to describe a high-speed train travelling along the artificial structures.
\end{abstract}

\section{Keywords:}

Bridge;

High-speed traffic;

Train and bridge interaction;

Dynamic factor;

Speed effect.

\section{Introduction}

When designing artificial structures on high-speed railway mainlines one should take into account strict requirements imposed to the structures of bridges, overpasses and cross-overs. These requirements concern reliability during the whole period of operation (durability), provision of uninterrupted traffic of high-speed and servicing rolling stock as well as passenger comfort.

One of the main peculiarities of bridge design on high-speed railways (HSR) is an obligatory requirement to account for the dynamic interaction of the high-speed rolling stock and the bridge structure. Meanwhile, unlike it is provided by the existing Russian standards [9], where the dynamic interactions in the 'bridge-train' system are calculated using a system of coefficients (a quasi-static model), at high-speed traffic the dynamic interaction factor should be accounted for by performing a dynamic task. Specificity of the rolling stock power load on the bridge structure is due to the so called speed effect or kinematic excitation, which means that the temporary power action caused by the bridge live load is transferred to the bridge superstructure via the wheel sets of the rolling stock. The most evident power action is posed on the bridge by trains consisting of single-type cars [3].

While operating an HSR bridge, the speed effect can cause a condition of resonance and lead to dangerous vibrations of the bridge structures. This occurs in case the period of train power action coincides with the main period of the bridge superstructure self-induced vertical vibrations. Upon that, the value of the dynamic live load factor caused by rolling stock increases significantly [8].

The dynamic effects not only result in the increase of stress within the bridge elements, but also they exert an unfavourable influence on the stability of the bridge deck and passenger comfort. 


\section{Methodology for the dynamic analysis of bridges}

In order to account for the dynamic nature of the live load stress one can apply various models of calculation. The simplest one is the quasi-static model, which means that the static live load stress is multiplied by the dynamic factor. According to the acting standards for conventional railways [9], the abovementioned factor is identified by formula:

$1+\mu=1+\frac{18}{30+\lambda}$, for metal superstructure,

$1+\mu=1+\frac{10}{20+\lambda}$, for reinforced concrete superstructure.

It should also be noted that the given formula is of empiric origin, does not account for the speed parameter and holds for designing bridges on conventional railways at speeds of no more than $200 \mathrm{~km} / \mathrm{h}$. formula:

European norms [11] define the dynamic factor as a sum total of two items according to the

$1+\mu=1+\mu_{1}+\mu_{2}$, for railways with standard track maintenance,

$1+\mu=1+\mu_{2}+0.5 \cdot \mu_{2}$, for railways with strict requirements for track maintenance,

$\mu_{1}=\frac{K}{1-K+K^{4}}$, at $K<0.76$,

$\mu_{1}=1.325$, at $K \geq 0.76$,

$K=\frac{V}{2 \cdot \lambda \cdot v}, \quad \mu_{2}=\frac{\alpha}{100}\left(56 \cdot e^{-\left(\frac{\lambda}{10}\right)^{2}}+50 \cdot\left(\frac{\lambda \cdot v}{80}-1\right) \cdot e^{-\left(\frac{\lambda}{20}\right)^{2}}\right) \geq 0, \alpha=\frac{V}{22}$,

where:

$\mu_{1}$ stand for the addition showing the dynamic interaction of the 'bridge-train' system;

$\mu_{2}$ stands for the dynamic addition accounting for the dynamic phenomena caused by track and wheel defects.

$V$ stands for the operational rolling stock speed, $\mathrm{m} / \mathrm{s}$;

$v$ stands for the first base bending frequency of the superstructure, $\mathrm{Hz}$;

$\lambda$ stands for the length of the influence line equal to the length of the beam superstructure span, $m$.

In European norms, the quasi-static approach to dynamic phenomena implies also the value of speed and dynamic features of the superstructure being calculated. However, it also limits its application to the speed of less than $200 \mathrm{~km} / \mathrm{h}$.

Limits for oscillation frequency according to the first form are showed on the graph (Fig. 1). The given frequency range corresponds with the range of the UIC-approved frequencies of the HSR bridge superstructure self-induced oscillations [3]. 


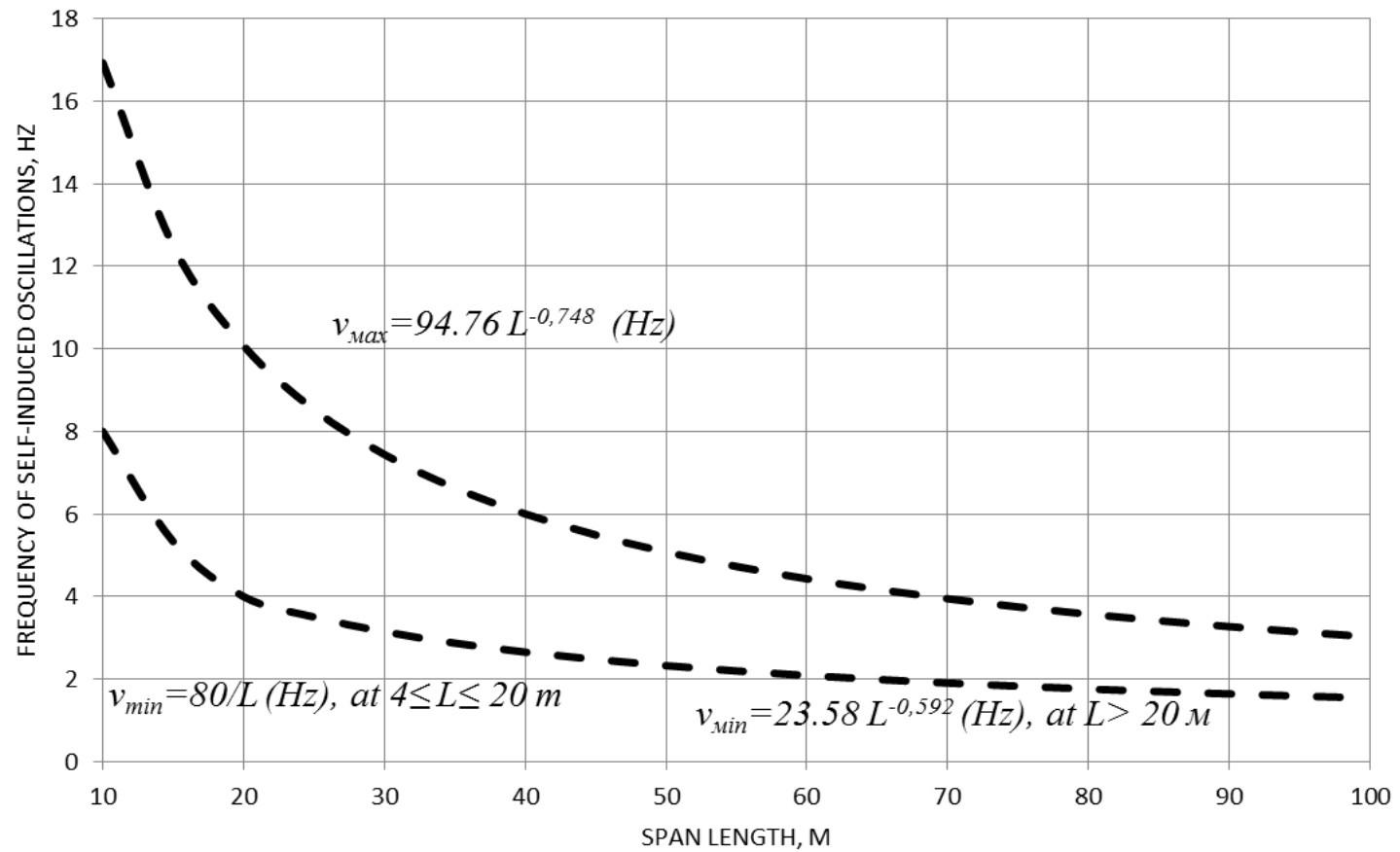

Fig. 1: The UIC-approved frequencies of the HSR bridge superstructure self-induced oscillations.

A comparison of the dynamic factors obtained by formulae from [9] and [11] is presented in Fig. 2.

To show the abovementioned dependences (Fig. 4), the highest and the lowest frequency values of the first beam superstructure bending self-frequency (Fig. 1) were applied. The design speed of the rolling stock is considered to be $200 \mathrm{~km} / \mathrm{h}$. On the graph one can see two pairs of curves under conditions of standard and improved track maintenance [8].

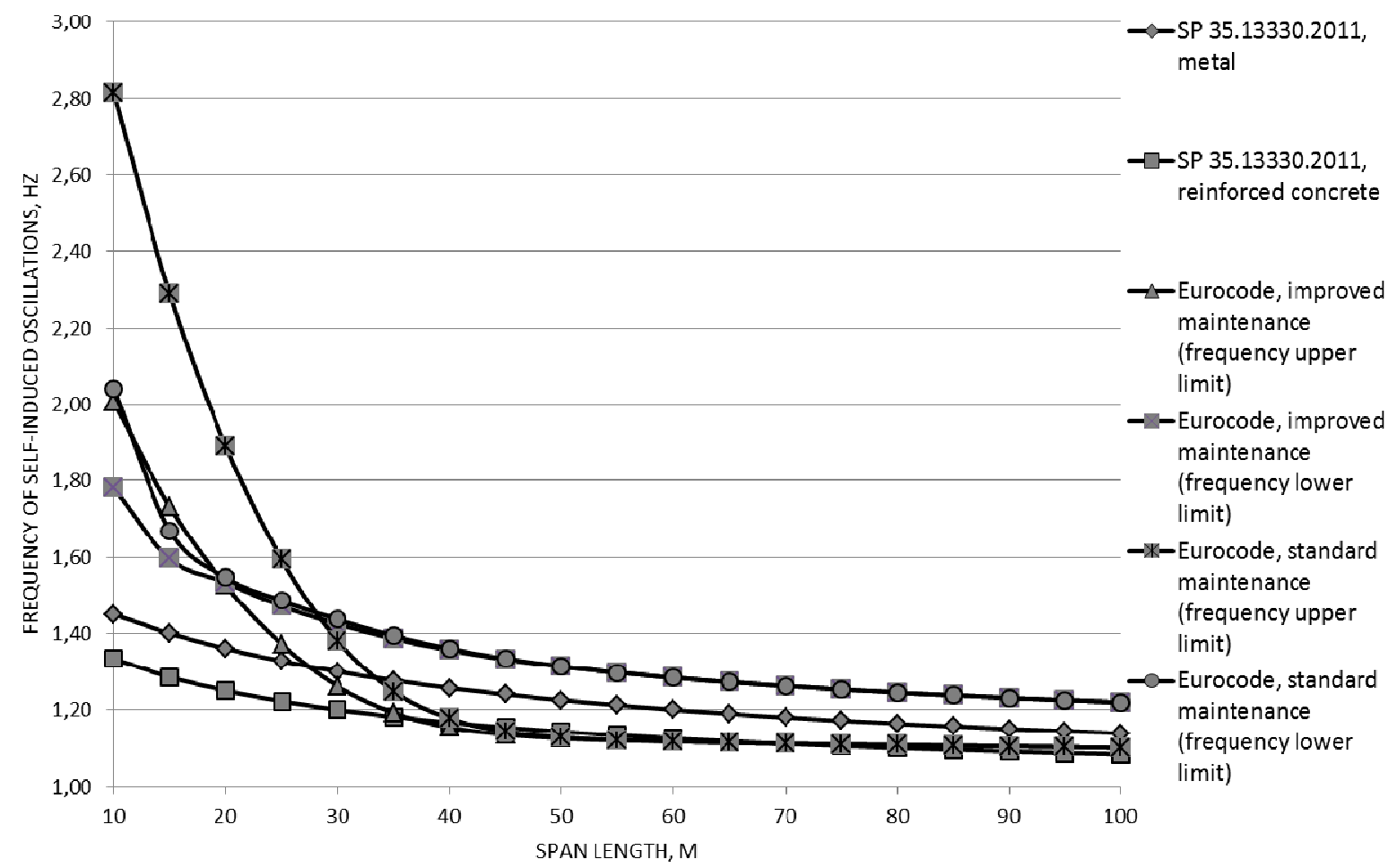

Fig. 2: Values of the dynamic live load factor in Russian and European standards and norms. 
Having analysed the graph in Fig. 2, one can see that the value of the dynamic factor calculated according to the European norms strongly depends on the quality of track maintenance. The most highly pronounced dynamic influence caused by track and wheel defects is exerted to spans of 20 - 45 m length with high self-frequencies.

The value of the first superstructure bending self-frequency determines the nature of general interaction between rolling stock and superstructure. For structures with low frequencies one can observe a higher value of the dynamic addition $\mu_{1}$ than for superstructures with high frequencies.

Thus, the decisive factor for bridge design is identification and rational assignment of the superstructure dynamic features, namely the parameters of the structure mass and rigidity.

Graphs showing dependence of the dynamic factor, which were obtained using Construction Code [9] for reinforced concrete and steel bridges, provide smaller values. This is due to the empiric origin of the given formulae. The empirical values of the dynamic additions were obtained in the middle of the 20th century by testing bridges under a live load moving at a speed of less than $200 \mathrm{~km} / \mathrm{h}$ [2]. The major specific shortcoming of the Russian standard comparing to the European one is the fact that it does not account for the dynamic phenomena determined by rail and wheel defects as well as for the superstructure dynamic features. It can be explained by predominance of standard superstructure bridges throughout the railway network, which in its turn results in the averaged nature of structural parameters and dynamic features.

It should be concluded, then, that such an approach is characterized by a number of serious drawbacks and has to be completely rethought of.

For higher operational train speeds it is necessary to perform direct dynamic calculations of the rolling stock impact on the superstructure. When performing dynamic calculations one can account for the dead load of the superstructure as well as for the live load caused to the structure by the rolling stock.

Standard vertical rolling stock loads used when performing dynamic calculations of artificial structures along the mainline comprise of a set of high-speed trains with design speed of up to $350 \mathrm{~km} / \mathrm{h}$. Calculations associated with the impact of high-speed rolling stock should be provided for any of the given trains: 10 trains A1 - A10 (analogue of HSLM - European norms), as well as for actual trains operating on domestic and international high-speed railways.

Table 1: Standard Trains' Parameters A1 - A10.

\begin{tabular}{|c|c|c|c|c|}
\hline \multirow{4}{*}{$\begin{array}{l}\text { Train } \\
\text { Option }\end{array}$} & \multicolumn{3}{|c|}{ Intermediate Cars } & \multirow[b]{2}{*}{$\begin{array}{l}\text { Load Magnitude } \\
\text { per Axle }\end{array}$} \\
\hline & $\begin{array}{c}\text { Number of } \\
\text { Cars }{ }^{1)}\end{array}$ & $\begin{array}{c}\text { Car } \\
\text { Length }\end{array}$ & $\begin{array}{c}\text { Bogie } \\
\text { Wheelbase }\end{array}$ & \\
\hline & $\mathrm{N}$ & I & $d$ & $P$ \\
\hline & items & $m$ & $\mathrm{~m}$ & $\mathrm{kN}$ \\
\hline $\mathrm{A} 1$ & 18 & 18 & 2 & 170 \\
\hline $\mathrm{A} 2$ & 17 & 19 & 3.5 & 200 \\
\hline A3 & 16 & 20 & 2 & 180 \\
\hline A4 & 15 & 21 & 3 & 190 \\
\hline A5 & 14 & 22 & 2 & 170 \\
\hline A6 & 13 & 23 & 2 & 180 \\
\hline A7 & 13 & 24 & 2 & 190 \\
\hline A8 & 12 & 25 & 2.5 & 190 \\
\hline A9 & 11 & 26 & 2 & 210 \\
\hline A10 & 11 & 27 & 2 & 210 \\
\hline
\end{tabular}

A dynamic task of the 'bridge-train' system interaction is solved mainly by means of computational simulation. Selection of a design model, thus, depends on the task assigned and - as a consequence - on the necessary specification of the 'bridge-train' system elements. It is possible to use various dynamic models [3]:

I. 'Moving powers on a beam' type. The superstructure is simulated with an elastic beam of finite mass and viscous damping, whereas the train is simulated with a system of moving powers (Fig. 3). Such a model allows to account for the speed effect and to obtain the critical speed values as well as peak values of the superstructure deformations and accelerations. 
II.'Moving masses on a beam' type. The superstructure is simulated similar to the model I, whereas the train is simulated with a system of moving masses with elastic and viscous restraints (Fig. 4). This approach allows to assess the extent of passenger comfort on the basis of acceleration analysis in the car bodies as well as the impact of track and wheel defects on the magnitude of the power of the rolling stock running gear dynamic interaction.

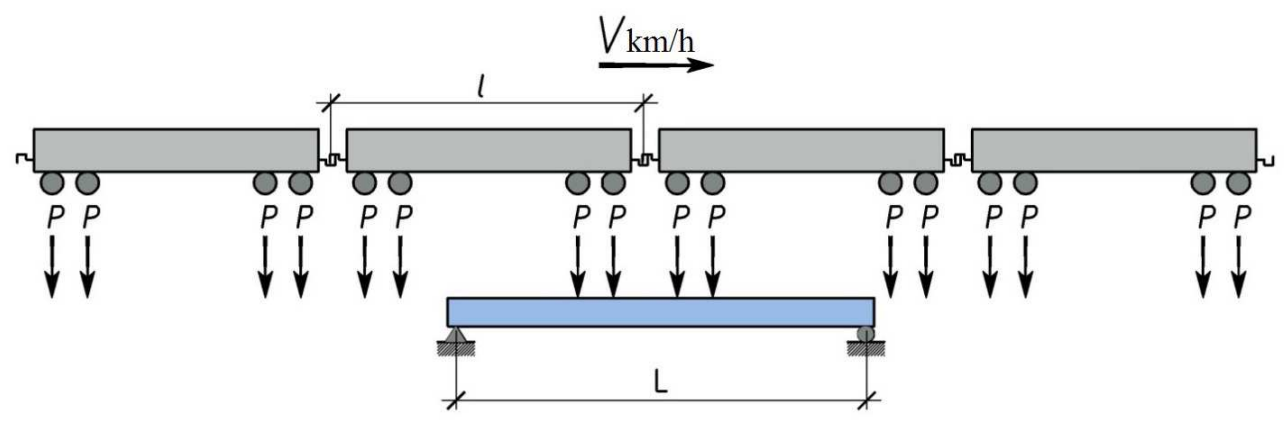

Fig. 3: A 'Moving Powers on a Beam' Model for Dynamic Calculations.

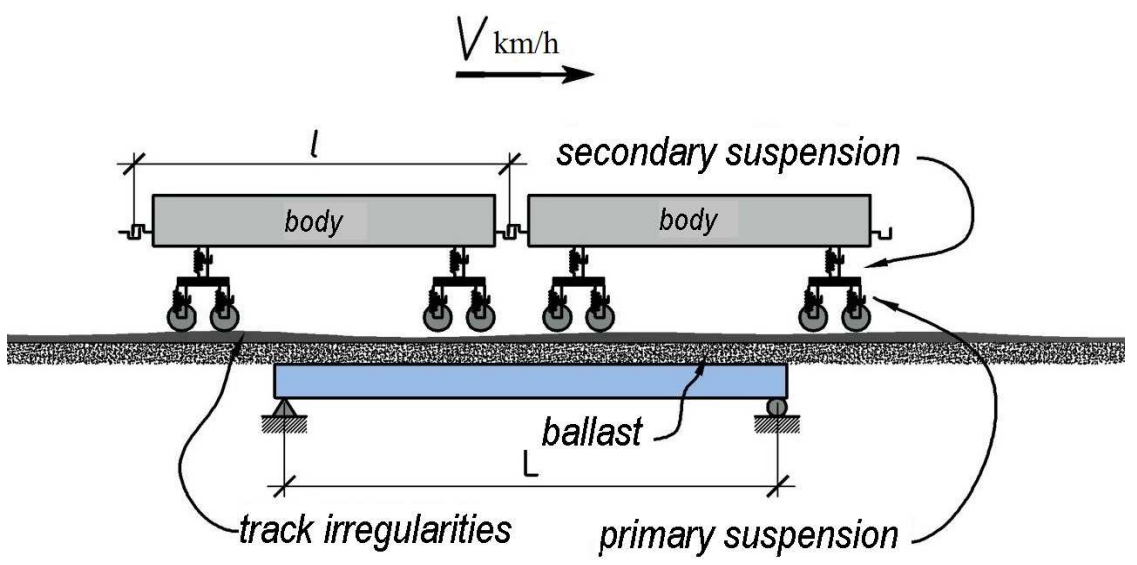

Fig. 4: A 'Moving Masses on a Beam' Model for Dynamic Calculations.

When creating a design model for calculating dynamic features of a structure, values of dynamic loads, deformations and responses in elements, one should take into account the following obligatory characteristics [10]:

- train speed;

- span length or influence line length for the element considered;

- structural elements weight;

- frequencies of the structure self-induced oscillations according to the corresponding oscillation forms;

- number of train axles, axle loads and intervals between axles;

- damping of the structure.

To provide more detailed simulations and to obtain information on the train cars behaviour the following should be additionally accounted for:

- sprung/unsprung weight and features of the rolling stock suspension;

- presence of elements that locally modify track rigidity (cross-beams, diaphragms, etc.) under track superstructure;

- defects of rails and wheels;

- track structure rigidity.

To calculate slab or beam girders in case there are no places with significant local changes in rigidity (roadway elements) under the roadway slab, the dynamic impact can be presented as a set of concentrated forces ('moving powers on a beam') moving along the structure at a set speed.

For bridges of different structure (frame bridges, arch bridges, truss bridges, etc.) one should perform dynamic calculations with account of interaction between a train and a structure (accounting 
for sprung/unsprung train weight, train bogie design as well as track structure rigidity and its interaction with the load-bearing part if necessary). In this case the 'moving masses on a beam' model should be applied.

\section{Dynamic live load factor for simply support bridges on high-speed railways}

When making calculations for simple span superstructures that are no longer than $60 \mathrm{~m}$ and satisfy the validity criteria for Model I, the dynamic high-speed load factor $\left(1+\mu_{1}\right)$ can be calculated by formula:

for $S_{p} \leq K_{2}: \quad 1+\mu_{1}=1+D f \cdot\left(\right.$ Dres $\left.^{\prime}-1\right) \cdot \exp \left(-0.5 \cdot\left(\left(S p-K_{2}\right) / 0.08\right)^{2}\right)$,

for $K_{2}<S_{p} \leq K_{1}: 1+\mu_{1}=$ Dres' $^{\prime}+\operatorname{Df} \cdot\left(\right.$ Dres - Dres $\left.^{\prime}\right) \cdot \exp \left(-0.5 \cdot\left(\left(\operatorname{Sp}-K_{1}\right) / 0.03\right)^{2}\right)$,

where $S_{p}$ stands for the speed parameter identified by formula:

$$
S p=V /\left(f_{1} \cdot L\right),
$$

$V(\mathrm{~m} / \mathrm{s})$ stands for the design speed;

$L(\mathrm{~m})$ stands for the design length of simple span superstructure;

$D$ stands for the car length of a design train;

$f_{1}(\mathrm{~Hz})$ stands for the frequency of superstructure oscillations according to the first form (for girder simple span superstructures);

Dres' stands for the dynamic high-speed factor at the second resonance speed identified by formula:

$$
\text { Dres' }^{\prime}=1.2+18.5 \cdot \exp (-2.5 K) \text {, }
$$

Dres stands for the dynamic high-speed factor at the first resonance speed identified by formula:

$$
\text { Dres' }^{\prime}=13+11.1 \cdot \sin (\pi(K+3) / 3.4)+1.65 \cdot \sin (\pi(K-0.53) / 0.59) \text {, }
$$

$K=L / D$ stands for the ratio of span length and car length of a design train;

$K_{2}=0.25 / K$ stands for the ratio of span length and car length of a design train at the second resonance;

$K_{1}=0.5 / K$ stands for the ratio of span length and car length of a design train at the main (first) resonance;

$D f$ stands for the damping parameter identified by formula:

$D f=1.65 \cdot \exp (-0.5(\zeta+\Delta \zeta))$

$\zeta(\%)$ stands for the lowest limit damping according to [10];

$\Delta \zeta(\%)$ stands for the additional damping [10].

During the calculation one should identify dependences of the dynamic factor for different values of parameter $K$ (ratio of span length and car length of a design train) on the value of speed parameter $S p$ for various values of speed $V$. In the further calculation the maximum value of the dynamic factor $\left(1+\mu_{1}\right)$ is adopted within the whole range of design speeds.

In order to simplify dynamic calculations of a high-speed train passage along the simple span superstructure of up to $60 \mathrm{~m}$ length the dependences of the dynamic factor $\left(1+\mu_{1}\right)$ on the structure and design train parameters were obtained by means of computational experiments.

In Fig. 5 and Fig. 6 one can find the results of computational experiments and the results obtained using the proposed formula. 


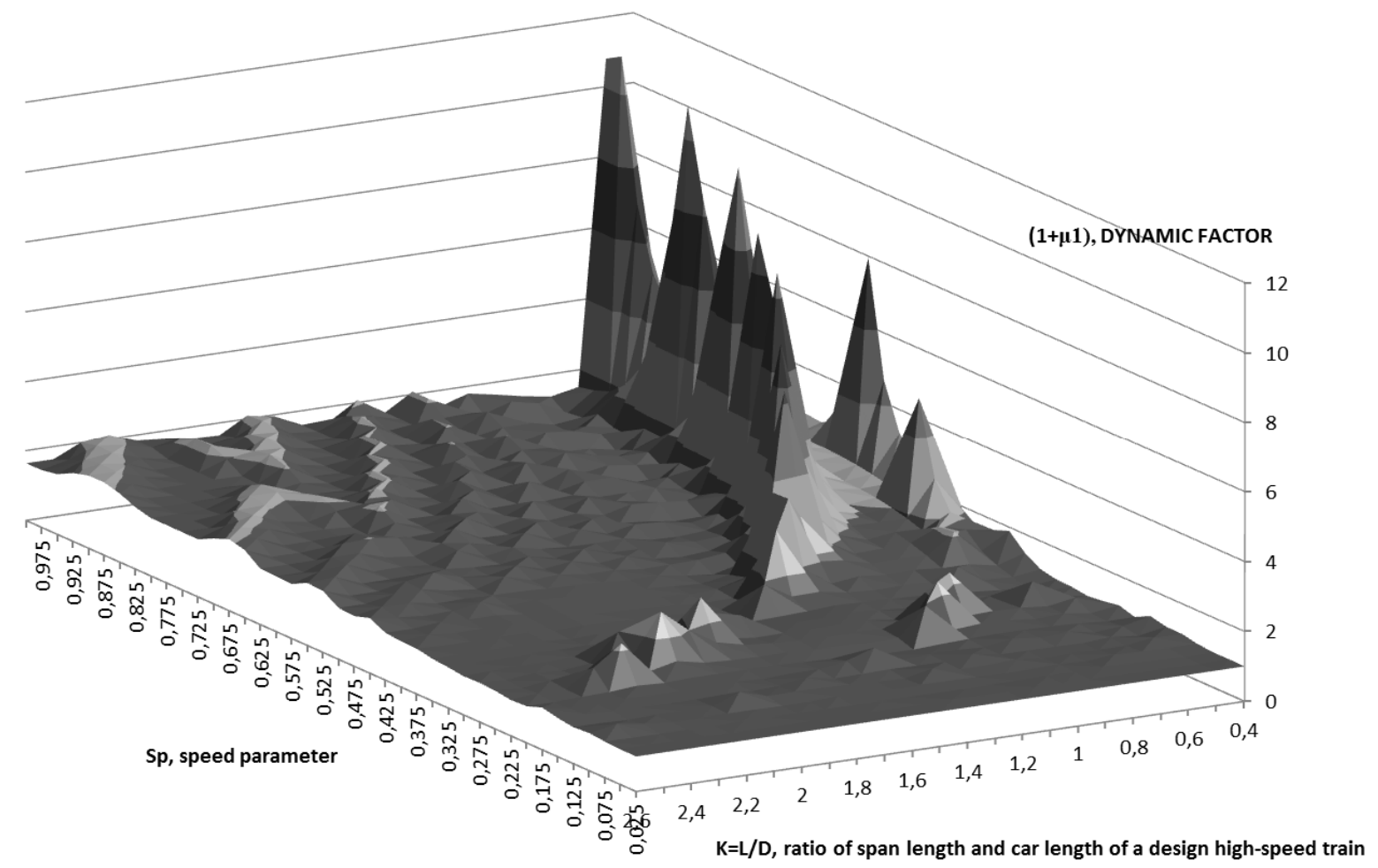

Fig. 5: Dependence of the dynamic factor on the superstructure and design train parameters obtained by means of computational experiments.

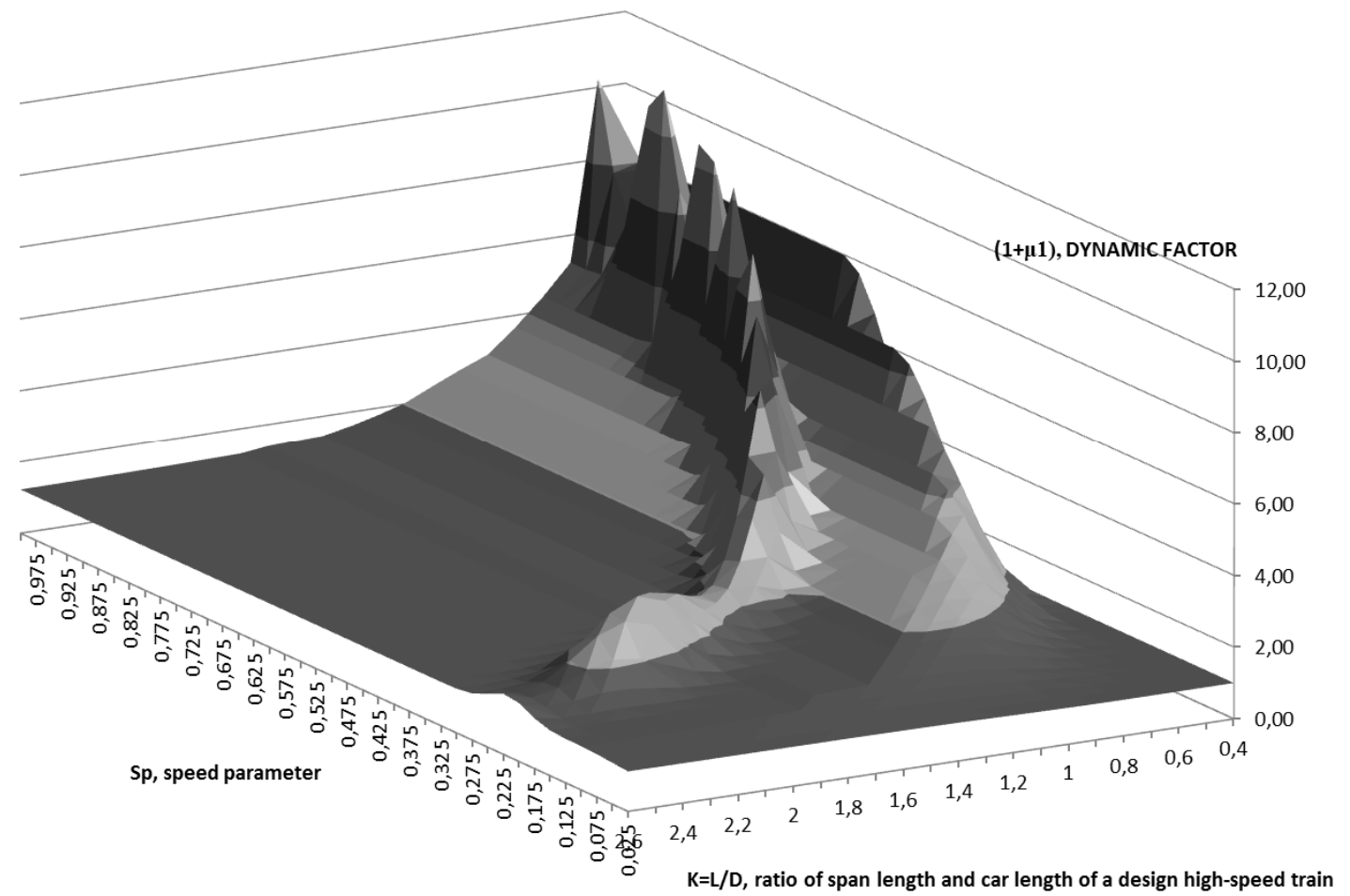

Fig. 6: Dependence of the dynamic factor on the superstructure and design train parameters obtained by means of formulae (8) and (9). 


\section{Conclusion}

According to the proposed methodology of calculation, one should identify dependences of the dynamic factor for different values of parameter $K$ (ratio of span length and car length of a design train) on the value of speed parameter $S p$ for various values of speed $V$. In the further calculation the maximum value of the dynamic factor $\left(1+\mu_{1}\right)$ is adopted within the whole range of design speeds.

\section{References}

[1] BENIN, A.V. - DYACHENKO, L.K. - SMIRNOV, V.N.: Design and construction peculiarities of the 'Moscow - Kazan' high-speed railway mainline (in Russian). In: Proceedings of St. Petersburg State Transport University, 2015, No. 4, (45), p. 15 - 20.

[2] BONDAR, N.G. - KOZMIN, Y.G. - REUTBURD, Z.G. et. al.: Interaction of the railway bridge with the rolling stock (in Russian). Moscow, 1984, $272 \mathrm{p}$.

[3] SMIRNOV, V.N. - BARANOVSKY, A.A. - BOGDANOV, G.I. - VOROBYEV, D.E. - DYACHENKO, L.K. - KONDRATOV, V.V.: Bridges on high-speed railways (in Russian). St. Petersburg, 2015, $274 \mathrm{p}$.

[4] SMIRNOV, V.N. - DYACHENKO, L.K. - EVSTIGNEEV, E.A.: Resonance oscillations of bridge superstructures on high-speed railway mainlines (in Russian). In: Proceedings of the International conference "New technologies in bridge building (from the past to the future)", St. Petersburg, 2015, p. $67-74$.

[5] SMIRNOV, V.N.: Peculiarities of high-speed express trains traffic along the bridges (in Russian). In: Proceedings of the International conference "New technologies in bridge building (from the past to the future)", St. Petersburg, 2015, p. 50 - 57.

[6] SMIRNOV, V.N. - BOGDANOV, G.I.: From the history of developing Technical specification for bridge design on the Moscow - Kazan HSR-2 (in Russian). In: Proceedings of the International conference "New technologies in bridge building (from the past to the future)", St. Petersburg, 2015, p. 57 - 67.

[7] KISELEV, I.P. - BLAZHKO, L.S. - BUSHUEV, N.S. - LEDYAEV, A.P. - SMIRNOV, V.N. - TITOVA, T.S. - FROLOV, Y.S. - BURKOV, A.T. - GAPANOVICH, V.A. - KOVALEV, V.I. - NIKITIN, A.B. PLEKHANOV, P.A. - SAVVOV, V.M. - SOKOLOV, Y.I. - SUKHODOEV, V.S.: High-speed Railway Transport: General Course (in Russian). Moscow, 2014, Vol. 1.

[8] CHIZHOV, S.V. - YAKHSHIEV, E.T. - DYACHENKO, L.K.: Appraisal of bride safety with account of the dynamic reliability factor (in Russian). In: Proceedings of St. Petersburg State Transport University, 2016, No. 2 (47), p. 247 - 254.

[9] DYACHENKO, L.K.: Dynamic calculations of HSR bridge superstructures for passenger trains running at the speed of up to $400 \mathrm{~km} / \mathrm{h}$ (in Russian). In: Proceedings of the International conference "New technologies in bridge building (from the past to the future)", St. Petersburg, 2015, p. $91-97$.

[10] SP 35.13330.2011. Construction Code 35.13330.2011. Bridges and Culverts. Actualized version of Construction Norms and Regulations 2.05.03-84* (in Russian).

[11] Technical specifications "Artificial structures on Moscow - Kazan section of Moscow - Kazan Ekaterinburg high-speed railway mainline" (in Russian). Design and construction norms and requirements, St. Petersburg, 2014.

[12] EN 1991-2 (2003): Eurocode 1: Actions on structures. P. 2: Traffic loads on bridges. 